\title{
Analysis of the image quality transmitted by an IPTV system
}

\author{
Danilo A. López $S^{\# 1}$, Jaime V. Avellaneda ${ }^{\# 2}$, Jordi R. Rodríguez ${ }^{\# 3}$ \\ ${ }^{\#}$ FullTime Professor at Universidad Distrital Francisco José de Caldas, \\ Faculty of Engineering, Bogotá (Colombia-South America) \\ dalopezs@udistrital.edu.co \\ ${ }^{\# 2}$ Electronic Engineering, Universidad Distrital Francisco José de Caldas, \\ Faculty of Engineering, Bogotá (Colombia-South America) \\ javallejo@correo.udistrital.edu.co \\ \#3 Electronic Engineering, Universidad Distrital Francisco José de Caldas, \\ Faculty of Engineering, Bogotá (Colombia-South America) \\ jordirico89@correo.udistrital.edu.co
}

\begin{abstract}
This article compares the results obtained when evaluating the PSNR (Peak Signal-to-Noise Ratio) metric when television and video content is delivered on demand on an IPTV-IMS platform using the RTSP and HTTP protocols. Several scenarios are evaluated for this. Initially, television is broadcast using the RTSP protocol, switching between wireless and wired networks and varying the network load. Later this process is repeated for the HTTP protocol and finally video is broadcast on demand repeating the load conditions and network type. Each of these scenarios starts with a user receiving the transmission and ends when 10 users are connected. The results of these tests are plotted and compared in order to determine the quality of the image received in the different scenarios implemented.
\end{abstract}

Keyword- Real Time Streaming Protocol (RTSP), Hypertext Transfer Protocol (HTTP), PSNR, MSE, IPTVIMS

\section{INTRODUCTION}

At present, one of the most demanding transmission flows in terms of resources in communications networks is related to the delivery of multimedia content (television and video on demand over IP). It is therefore important to investigate, study and evaluate the level of quality with which the signals or images reach the receivers or end users. For this reason, this article presents the results found when evaluating the PSNR metric in order to determine the relationship between the maximum energy of a signal (image) versus background noise; and for this the present article is divided into three large Sections that includes the design of the IPTV platform on which the tests were carried out, to subsequently share the results found and the final conclusions.

\section{IPTV PLATFORM DESIGN.}

For the implementation of an IPTV platform, there must be a minimum of entities that guarantee the correct functioning of the platform. Initially, an IMS core must be available, which was implemented in software through the Open IMS Core [1] and which includes three call session control entities (CSCF) and a user database. However, three more elements are required, which are what will ultimately shape the implementation of an IPTV system. These elements correspond to the IPTV application server (IPTV AS), the IMS Client and the Media Server. The first two as well as the core have been developed in free code by the Communications Research Group of the University of Cape Town [2] in South Africa.

The IPTV application server developed under the name of UCT IPTV Advanced allows loading the address table in which the search of the selected contents will be carried out.

Regarding the IMS client, there are several free code options available to work with the selected project, which have different characteristics [2]. However, the only one that supports IPTV is the UCT IMS Client, which has a simple interface in which there are several options such as client registration, preference settings, different call options, video call, instant messaging and request of channels or videos available. However, this client is only available for computers, so if you want to establish a session or request content within this environment from a TV, you must use a Top Box Set that integrates an IMS agent or otherwise use a common Top Box Set with a middleware that supports IMS and allows connection to the core. There are other options such as connecting the Top Box Set to an intermediate Gateway with an IMS termination but the final choice depends on the needs, resources and availability of devices in the market.

For the media server there are several options both licensed and open source that can be used and that are compatible with the Open IMS Core. It must be taken into account before selecting it that it must support multicast transmission since it is one of the features that stand out in this service. 
Regarding the client, it is intended that this service be provided both in computers and televisions. Due to this, the platform will be implemented in two different ways. The first will be the IMS architecture mentioned for the visualization of content in computers while for televisions a platform without NGN or IMS will be used, that is, the Top Box Set will connect directly to the content server. However, the basic requirements established by the ITU [3] for IPTV are taken into account, for the choice of the Top Box Set, for which, after searching and comparing the products available in the market, the AXWELL IPTV125 was selected (Fig. 1) since it works on free code and additionally supports the selected media server and includes the VoD and Time Shifting applications. The specifications appear in the operation manual.

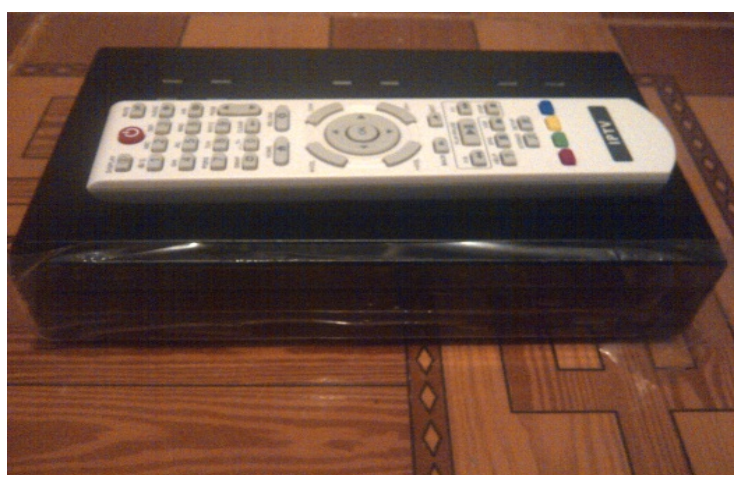

Figure 1. AXWELL Top Box Set IPTV125.

The difference with the platform in computers will be in the lack of some services such as the authentication phase and content discovery, video call and instant messaging which will not be necessary in this case since no user will interact with the televisions. Finally (although it has not been named so far), it is necessary to implement a domain name server (DNS) that will be responsible for communicating the entities with each other. For this the BIND package was selected since it is a free code option ready to use in Linux and has great web support. This server must be modified in its address table according to the new addressing so that the entities can communicate.

The final IPTV system design is presented in Fig. 2.

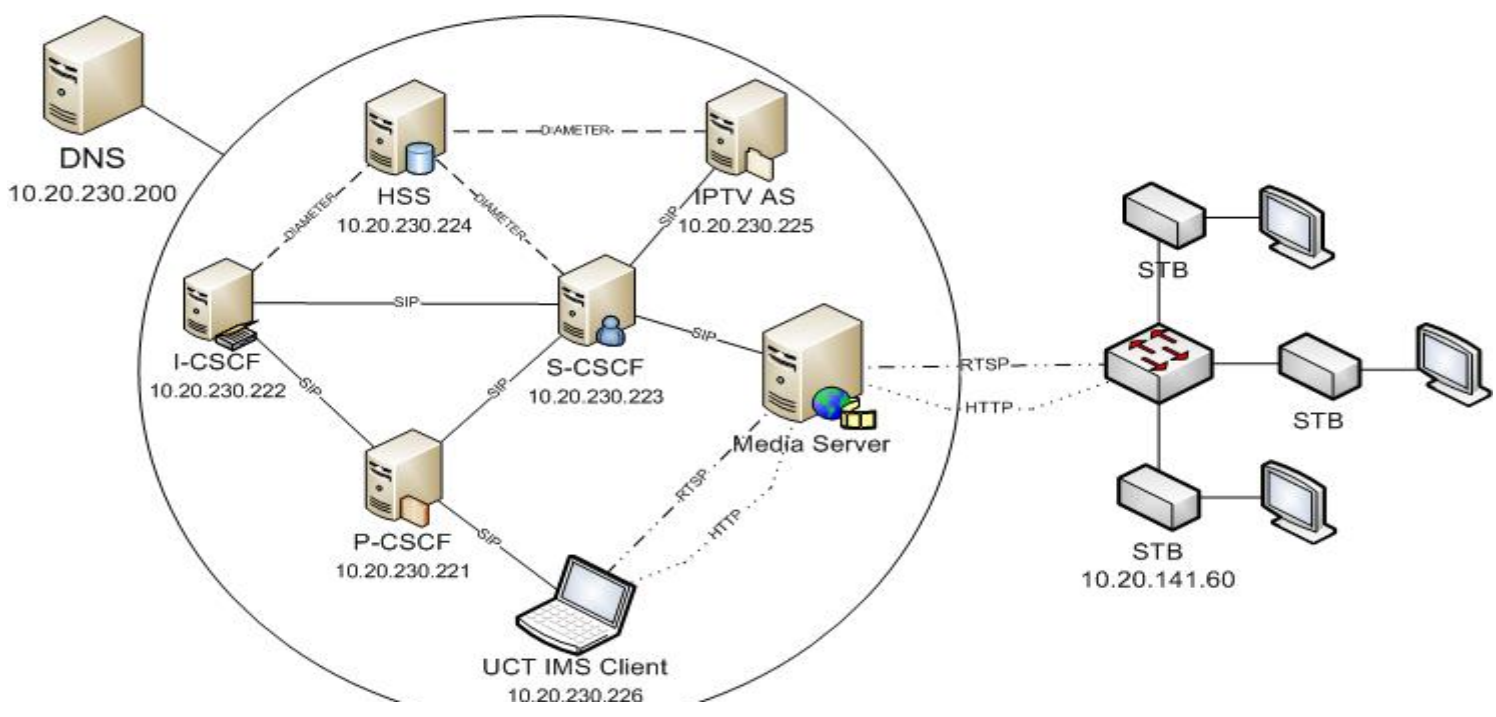

Figure 2. IPTV platform design.

\section{RESUlts.}

Para la medición de la variable que permite evaluar la calidad de las imágenes transmitidas se hizo uso del software científico MATLAB mediante el cálculo de la relación señal a ruido en la imagen recibida utilizando el indicador PSNR (Peak Signal-to-Noise Ratio) el cual determina la relación entre la máxima energía de una señal frente al ruido de fondo. Para calcular este indicador se utilizó el Mean Square Error (MSE) entre la imagen original enviada y la imagen codificada recibida [4]. El MSE y el PSNR están dados por las siguientes ecuaciones: 
For measuring the variable that allows to evaluate the quality of the transmitted images, MATLAB scientific software was used by calculating the signal-to-noise ratio in the image received using the PSNR (Peak Signalto-Noise Ratio) indicator, which determines the relationship between the maximum energy of a signal versus background noise. To calculate this indicator, the Mean Square Error (MSE) was used between the original image sent and the received encoded image [4]. The MSE and the PSNR are given by the following equations:

$$
\begin{aligned}
& \text { MSE }=\frac{1}{\mathrm{~m} * \mathrm{n}} \sum_{\mathrm{i}=0}^{\mathrm{m}-1} \sum_{\mathrm{j}=0}^{\mathrm{n}-1}\|\mathrm{I}(\mathrm{i}, \mathrm{j})-\mathrm{K}(\mathrm{i}, \mathrm{j})\|^{2} \\
& \text { PSNR }=10 * \log _{10}\left(\frac{(\text { Máximo valor del pixel })^{2}}{\text { MSE }}\right)
\end{aligned}
$$

where:

$\mathrm{I}=$ Original image sent

$\mathrm{K}=$ Coded image received

$\mathrm{m}=$ Horizontal size of the image in pixels

$\mathrm{n}=$ Vertical size of the image in pixels

It should be noted that this value is given in $\mathrm{dB}$ and the larger the better the quality of the video received since the image will be closer to the original. In general, it can be said that any PSNR exceeding $30 \mathrm{~dB}$ presents a more reliable image [5].

A. Perception analysis of the transmitted image quality.

As mentioned above, one of the most important factors to know the quality of the transmitted image is the PSNR, which indicates the peak signal to noise ratio existing in it. The measure of this indicator is very relative since it will not always change in a constant way, so obtaining a model that approximates its behavior will not be of great help. However, this can be evaluated to have an idea of how it will be affected according to the services, protocols and number of users.

Figures 3 to 10 show the PSNR values except for those obtained in televisions since there are two unique values per scenario and they do not present variation [6].

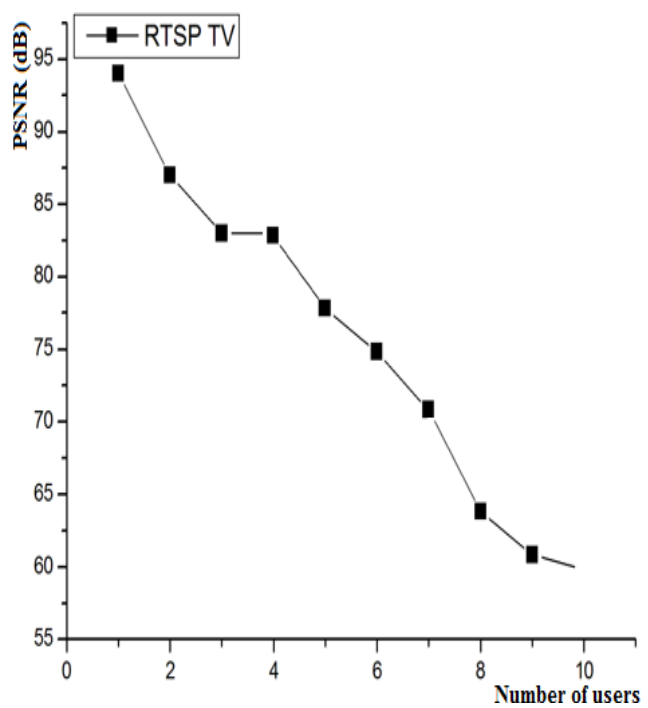

Figure 3. PSNR for Television sent through RTSP protocol through wireless network.

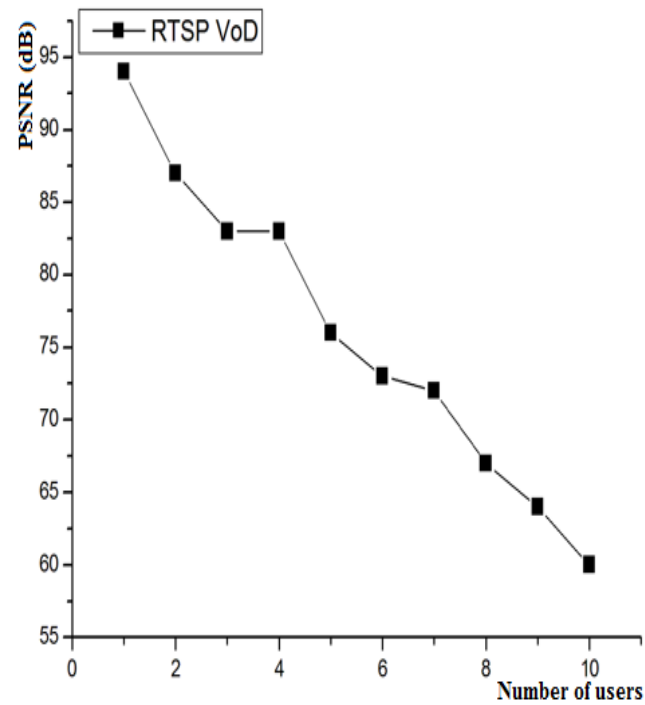

Figure 4. PSNR for VoD sent via RTSP protocol through wireless network. 


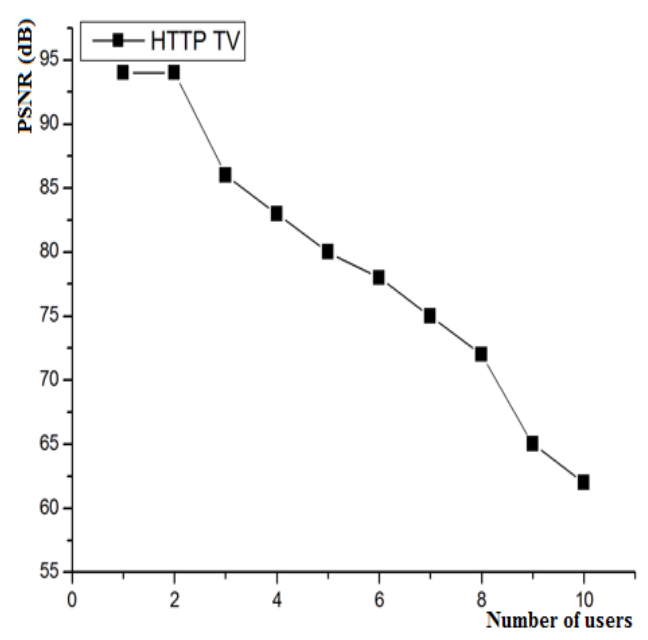

Figure 5. PSNR for Television sent via HTTP protocol over wireless network.

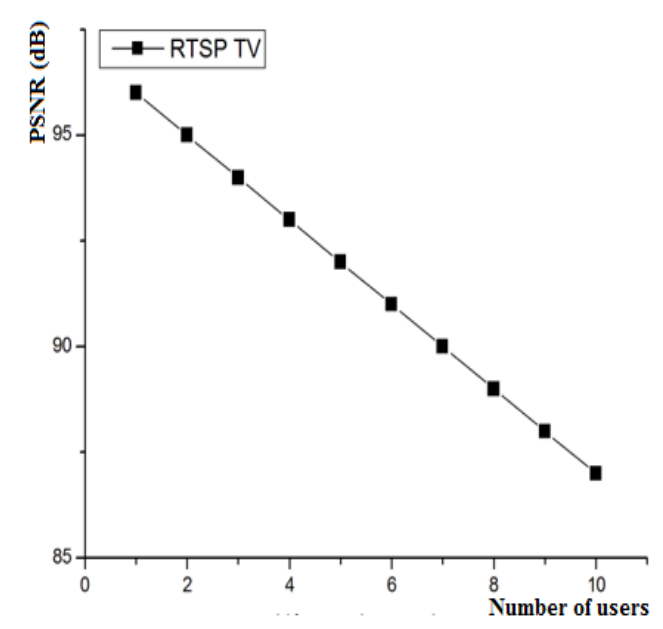

Figure 7. PSNR for Television sent through RTSP protocol through wired network.

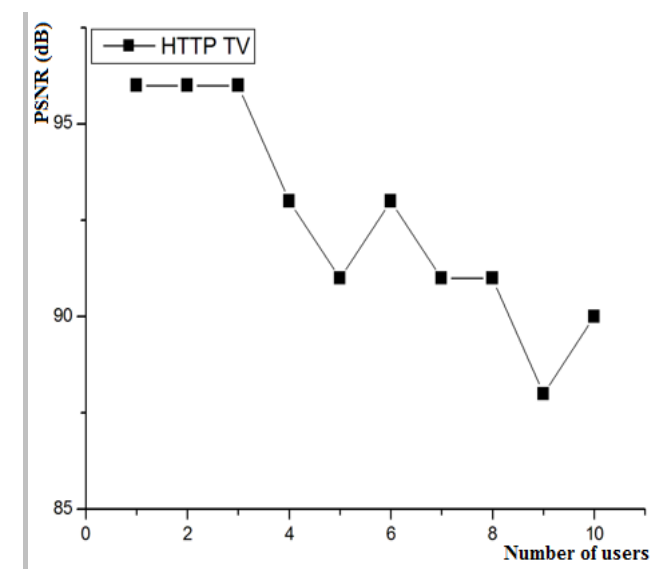

Figure 9. PSNR for Television sent by HTTP protocol through wired network.

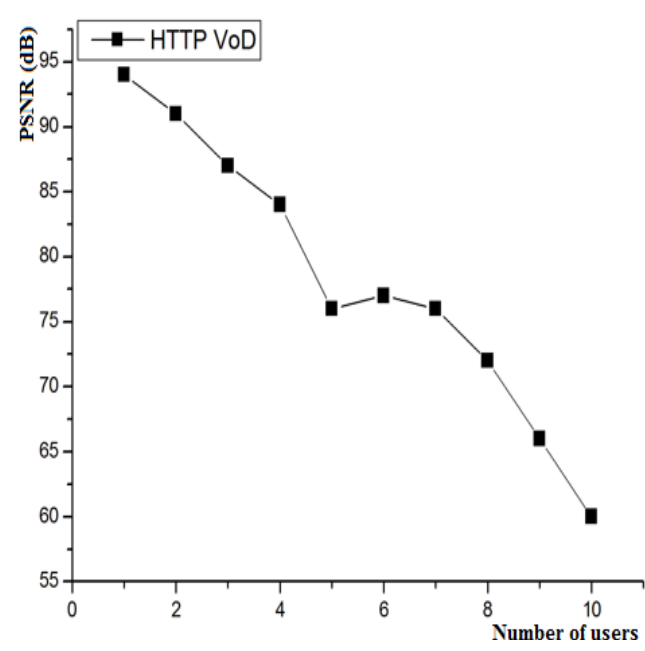

Figure 6. PSNR for VoD sent via HTTP protocol over wireless network.

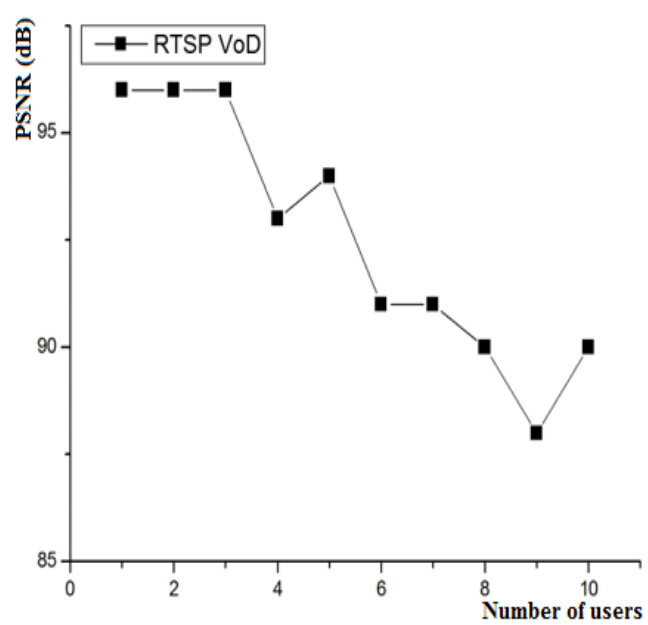

Figure 8. PSNR for VoD sent by RTSP protocol through wired network.

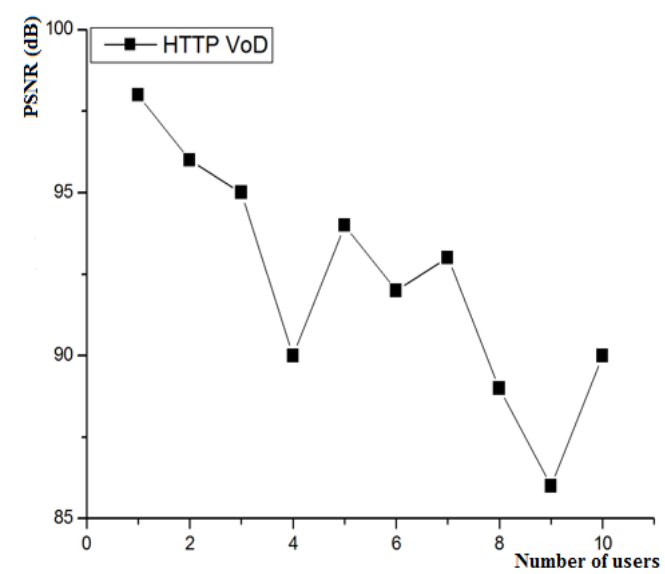

Figure 10. PSNR for VoD sent via HTTP protocol over wired network. 
The previous figures show that the PSNR value decreases almost linearly as the number of users connected to the services delivered increases. However, there are cases in which this indicator increases or varies in a random way as users increase (especially in the cases of television and video on demand (VoD) over HTTP protocol using the wired network as shown in Fig. 9 and Fig. 10, which is due to the variation of the network load.

\section{B. Discussion.}

When evaluating the PSNR indicator on the wireless network (Fig. 3 to Fig. 6) it can be seen that its value decreases with increasing number of users; additionally it is concluded that its value is a little higher when video services are delivered on demand. This is due to the fact that by increasing the number of simultaneous transmissions, the content server is more demanding and therefore the encoding of the video is affected.

However, the values in all cases exceed the minimum of $30 \mathrm{~dB}$ and are very close to each other, so it can be concluded that the encoded and delivered video presents good quality regardless of the scenario given its high similarity to the original content. It should also be noted that this value does not differ much between the protocols that were used to carry out the transmissions (HTTP and RTSP), which indicates that both have good received image quality.

When evaluating the PSNR indicator on the wired network (Fig. 7 to Fig. 10) it is observed a slight increase in the indicator with respect to the values obtained by wireless network. In theory they should be the same since the coding is done in the same way in both cases. However, the noise presented in the wireless network affects the image delivered to the user, which causes this value to be diminished.

Despite this, the values continue to exceed the already defined minimum, so the quality continues to be good.

\section{CONCLUSIONS}

For the implementation of the IPTV platform, an IMS architecture was selected as it is a booming technology for the transmission of multimedia content, with various free code options for its implementation and additionally it has great flexibility allowing its extension to different environments and the creation or implementation of applications according to the needs that present themselves.

The protocols selected for carrying out the tests were RTSP and HTTP since they are two of the most important standards for the transmission of multimedia content in platforms of this type. Each one works on different transport layers and the results allowed to see their effect on the evaluation of the PSNR metric as described in Section 3.2.

With the culmination of this research work, the academic community is given an important advance in IPTV on which new developments, research and degree projects can be carried out. The possibility of implementing the evaluation of the quality of the image perceived by cognitive and primary users in a cognitive radio network [7] and [8] is left for study and subsequent investigation.

\section{ACKNOWLEDGMENTS}

This research was carried out thanks to the sponsorship given by the Center for Research and Scientific Development (CIDC) of the District University.

\section{REFERENCES}

[1] J. Avellaneda, J. Rodríguez, D. López, Servicios de televisión sobre la plataforma de Internet (IPTV-IMS) usando protocolo de flujo en tiempo real (RTSP) y protocolo de transferencia de hipertexto, Revista Información tecnológica, Volume 25, Issue 1, pp. 67-77, 2014.

[2] Network information library - Six open source IMS clients feature overview, The table provides features overview of six open source IMS clients. [Online]. Recovered from: http://nil.uniza.sk/ngnims/six-open-source-ims-clients-features-overview-february-2012, 2012.

[3] International Telecommunication Union (ITU), IPTV Standarization at ITU-T. [Online]. Recovered from: https://www.itu.int/en/ITUT/gsi/iptv/Documents/tech/1002-Singapore-IDA-APT-WS-IPTV-Overview.pdf, 2007.

[4] C. Granda, C, Caracterización, evaluación y optimización de sistemas multimedia en entornos de e-learning síncrono. Cap 5, Valoración del funcionamiento. Doctoral Thesis. Oviedo University, 2008.

[5] A.Amer, A. Mitiche, E. Dubois, Reliable and fast structure-oriented video noise estimation, Proceedings. International Conference on Image Processing, Volume 1, pp.I-840,I-843, 2002.

[6] J.Vallejo, J. Rico, Diseño e implementación de una plataforma experimental IPTV para la Universidad Distrital y generación de un modelo de pérdidas, Undergraduate Thesis, Universidad Distrital, Bogotá, Colombia, 2013.

[7] D. López, E. Rivas, O. Gualdron, Primary user characterization for cognitive radio wireless networks using a neural system based on Deep Learning, Journal Artificial Intelligence Review (Early Access), pp. 1-27, 2017. doi: 10.1007/s10462-017-9600-4.

[8] D. López, C. Anzola, D. Zapata, E. Rivas, Designing a MAC algorithm for equitable spectrum allocation in cognitive radio wireless networks, Journal Wireless Personal Communications 2017, Volume 98, Issue. 1, pp. 1-32, 2017. 